\title{
The Changing Epidemiological Profile of HIV-1 Subtype B Epidemic in Ukraine
}

\author{
Tetyana I. Vasylyeva, ${ }^{1}$ Mariia Liulchuk, ${ }^{2}$ Louis du Plessis, ${ }^{1}$ Esther Fearnhill, ${ }^{3}$ Victoriia Zadorozhna, \\ Nataliia Babii, ${ }^{2}$ Alla Scherbinska, ${ }^{2}$ Vladimir Novitsky, ${ }^{4}$ Oliver G. Pybus, ${ }^{1}$ and Nuno R. Faria ${ }^{1}$
}

\begin{abstract}
While HIV-1 subtype B has caused a large epidemic in the Western world, its transmission in Ukraine remains poorly understood. We assessed the genetic diversity of HIV-1 subtype B viruses circulating in Ukraine, characterized the transmission group structure, and estimated key evolutionary and epidemiological parameters. We analyzed $120 \mathrm{HIV}-1$ subtype B pol sequences (including 46 newly generated) sampled from patients residing in 11 regions of Ukraine between 2002 and 2017. Phylogenies were estimated using maximum likelihood and Bayesian phylogenetic methods. A Bayesian molecular clock coalescent analysis was used to estimate effective population size dynamics and date the most recent common ancestors of identified clades. A phylodynamic birth-death model was used to estimate the effective reproductive number $\left(R_{e}\right)$ of these clades. We identified two phylogenetically distinct predominantly Ukrainian $(\geq 75 \%)$ clades of HIV-1 subtype B. We found no significant transmission group structure for either clade, suggesting frequent mixing among transmission groups. The estimated dates of origin of both subtype B clades were around early 1970s, similar to the introduction of HIV-1 subtype A into Ukraine. $R_{e}$ was estimated to be 1.42 [ $95 \%$ highest posterior density (HPD) 1.26-1.56] for Clade 1 and 1.69 (95\% HPD 1.49-1.84) for Clade 2. Evidently, the subtype B epidemic in the country is no longer concentrated in specific geographical regions or transmission groups. The study results highlight the necessity for strengthening preventive and monitoring efforts to reduce the further spread of HIV-1 subtype B.
\end{abstract}

Keywords: HIV-1, $\mathrm{B}_{\mathrm{FSU}}$, Ukraine, molecular epidemiology, people who inject drugs

\section{Introduction}

$\mathbf{U}$ KRAINE HAS ONE OF THE worst HIV epidemics among European countries: in 2015, the country had the highest rate of new HIV infections in Europe ( $~ 30$ cases per 100,000 people). ${ }^{1}$ In the 1990 s, people who inject drugs (PWID) were the transmission group that accounted for majority of new HIV infections in Ukraine. ${ }^{2,3}$ However, since the late 2000s, transmission among heterosexual nondrug-injecting populations has prevailed. ${ }^{4}$

Even though HIV-1 subtype B and CRF03_AB (the latter first found in the Russian city Kaliningrad ${ }^{5}$ ) were circulating in the country since the 1990s, the majority of HIV-1 infec- tions in Ukraine are caused by HIV-1 subtype A. ${ }^{6,7}$ In 2015, $89 \%$ of HIV-1 sequences in the Ukrainian HIV database, a drug resistance screening database containing sequences from HIV patients in Ukraine, were identified as HIV-1 subtype A. ${ }^{8}$ Similarly, $88 \%$ of Ukrainian sequences in the Los Alamos HIV sequence database are classified as HIV-1 subtype A. ${ }^{9}$ To date, most molecular epidemiology studies of the Ukrainian epidemic have focused on HIV-1 subtype A in PWID populations. ${ }^{10-12}$

HIV-1 subtype B, which is the most prevalent HIV subtype in most Western European countries, has limited distribution and prevalence in Ukraine compared with HIV-1 subtype A. In 2012-2015, 4\% (19 of 448) of sequences in the Ukrainian

\footnotetext{
${ }^{1}$ Department of Zoology, University of Oxford, Oxford, United Kingdom.

${ }^{2}$ L.V. Gromashevskij Institute of Epidemiology and Infectious Diseases of National Academy of Sciences of Ukraine, Kyiv, Ukraine.

${ }^{3}$ Institute for Global Health, University College London, United Kingdom.

${ }^{4}$ Department of Immunology and Infectious diseases, Harvard TH Chan School of Public Health, Boston, Massachusetts.
}

(c) Tetyana I. Vasylyeva et al. 2019; Published by Mary Ann Liebert, Inc. This Open Access article is distributed under the terms of the Creative Commons License (http://creativecommons.org/licenses/by/4.0), which permits unrestricted use, distribution, and reproduction in any medium, provided the original work is properly cited. 
Drug Resistance database were identified as HIV-1 subtype $\mathrm{B},{ }^{8}$ as were $<10 \%$ of Ukrainian sequences in the Los Alamos HIV database. ${ }^{9}$ However, extrapolation of these rates $(4 \%-$ $10 \%$ ) to the estimated $220,000 \mathrm{HIV}$-infected people in the country ${ }^{1}$ suggests that HIV-1 subtype B accounts for about 9,000-22,000 HIV infections in Ukraine.

The genetic diversity of HIV-1 subtype B in Ukraine seems to be characterized by two different cocirculating lineages: one is diagnosed mostly in PWID and characterized by very low genetic diversity, while another is more genetically similar to subtype B strains observed in Western European countries. ${ }^{7,13}$ The first lineage was not only reported mainly in Mykolaiv, a port city in the south of Ukraine, but was also observed in some other countries of the former Soviet Union (FSU) and was subsequently called $\mathrm{B}_{\mathrm{FSU}}{ }^{7,14}$ Two studies from Russia and Azerbaijan have shown that local HIV-1 subtype B infections among PWID clustered with viral sequences previously diagnosed in patients in Mykolaiv and Kyiv. ${ }^{15,16}$ A recent study demonstrated high levels of phylogenetic clustering (66\%) among men who have sex with men (MSM) and heterosexual men infected with HIV-1 subtype B in Kyiv, the capital of Ukraine. ${ }^{17}$

The epidemiology of HIV-1 subtype B transmission across transmission groups, such as MSM and PWID, and among geographic regions in Ukraine remains poorly understood. In this study, we describe the dynamics of the HIV-1 subtype B epidemic in 11 Ukrainian regions between 2002 and 2017. We apply molecular epidemiological methods to estimate the dates of introduction of HIV-1 subtype B into Ukraine and assess the transmission dynamics of the most prevalent HIV1 subtype B lineages.

\section{Materials and Methods}

Data

Genetic data. Ukrainian HIV-1 subtype B genetic sequences were derived from three sources. First, we report 46 new HIV-1 subtype B pol gene sequences from patients visiting Ukrainian AIDS centers (the hospitals for HIV treatment and care) in 2012-2017, which were made available through the Ukrainian HIV drug resistance database. These data were sequenced at the L.V. Gromashevskij Institute of Epidemiology and Infectious Diseases in Kyiv using the ViroSeq ${ }^{\circledR}$ HIV-1 Genotyping System, v2.0, Kit (Celera Corporation, Abbott). These 46 sequences represent 11 administrative regions of Ukraine: Mykolaiv $(N=24)$, Kyiv $(N=6)$, Odessa $(N=3)$, Vinnytsya $(N=3)$, Dnipro $(N=2)$, Kharkiv $(N=2)$, Sumy $(N=2)$, and Ivano-Frankivsk, Kherson, Lugansk, and Zhytomyr ( $N=1$ each). Second, we used 73 HIV-1 subtype B pol sequences collected as part of the CASCADE (Concerted Action on SeroConversion to AIDS and Death in Europe) cohort study in Kyiv in 2013 2015. ${ }^{17}$ These data were collected anonymously in four infectious disease clinics that are part of the Kyiv AIDS Centre $^{18}$ and were sequenced at University College London Hospital laboratories on Sanger or Illumina MiSeq platforms. Third, we accessed the Los Alamos HIV database ${ }^{9}$ and retrieved all available HIV-1 subtype B sequences $(N=9)$ collected in Ukraine that spanned the same genomic region (HXB2 positions: 2,568-3,256) and which had available sampling dates and transmission group information. Only HIV-1 subtype B sequences with $<5 \%$ ambiguous nucleo- tides were used. Duplicate sequences were removed using the ElimDupes tool from the Los Alamos website (https://www .hiv.lanl.gov). We used the REGAv3 ${ }^{19}$ and COMET ${ }^{20}$ subtyping tools to confirm correct HIV subtype assignment.

After removing duplicates, the Ukrainian dataset contained 120 HIV-1 subtype B sequences with matching sociodemographic and epidemiological data (gender, transmission group, date of sampling, and city of sampling). We then downloaded the 10 closest reference sequences to the sequences in the Ukrainian dataset using the $\mathrm{BLAST}^{21}$ tool from the Los Alamos database website. After removing duplicates, these sequences and the Ukrainian dataset composed the combined dataset ( $N=299$ sequences). Information on reference sequences (country, date of sampling, and accession numbers) is provided in Supplementary Table S1.

Alignment. We codon-aligned the sequences using Clustal Omega $^{22}$ and then manually edited the alignment using MEGA. ${ }^{23}$ We deleted 43 codon positions associated with drug resistance. ${ }^{24}$ The final alignment consisted of 614 nucleotides that correspond to nucleotide positions 2,5683,256 of the HXB2 HIV reference sequence (pol gene). Mean pairwise genetic distances were calculated using MEGA.

Epidemiological data. The annual number of all newly registered HIV infections (all subtypes) by transmission group was available from the Ministry of Health website of Ukraine. ${ }^{3}$ Annual data were available starting from 1995.

Statistical analysis. To test for possible associations between sociodemographic and other characteristics, and the membership of sequences in the dominant circulating clades, we performed chi-square tests (for variables with expected cell values 25 ) and Fisher's exact tests (for variables with expected cell values $\leq 5$ ). To account for multiple comparisons between different groups of the same variable, we used Bonferroni multiple test correction: only $p$ values $\leq(.05 /$ the number of categories in the variable) were considered significant.

\section{Phylogenetic analysis}

Maximum likelihood phylogenies. We estimated maximum likelihood (ML) phylogenetic trees for the Ukrainian and the combined datasets using RAxML. ${ }^{25}$ We used a general time-reversible (GTR) nucleotide substitution model with gamma-distributed rate variation among sites. In the combined dataset, we identified two clades with $>50$ sequences, at least $75 \%$ of which were from Ukraine. Both clades exhibited $\mathrm{SH}$-like statistical support values $>0.80,{ }^{26}$ which are considered statistically significant. ${ }^{27}$ We used RAxML to estimate ML trees for both clades after removing sequences that were not sampled in Ukraine. We used TempEst ${ }^{28}$ to evaluate root-to-tip divergence in the combined dataset and for the two Ukrainian clades.

We used $\mathrm{BaTS}^{29}$ to calculate the association index (AI) for phylogenies of the two Ukrainian clades. The AI is a statistic that describes the association between a phylogeny and traits at its tips (transmission groups in our case). BaTS also provides statistical support ( $p$ values) for the AI statistic by 
comparing values obtained from the posterior tree distribution with those obtained by randomly reassigning traits at the tips (100 times).

Time-calibrated phylogenies. We estimated evolutionary parameters and time-calibrated phylogenies using the BEAST, v1.8.4, software package. ${ }^{30}$ The combined dataset was used to estimate the time of the most recent common ancestor (TMRCA) of the two Ukrainian clades. To identify the most appropriate coalescent and molecular clock models, we used path-sampling ${ }^{31}$ and stepping stone $^{32}$ marginal likelihood estimators. We assessed the fit of two molecular clock models (strict and lognormal relaxed) and three coalescent demographic models (constant population size, exponential growth, and Bayesian skyline). The Bayesian skyline model ${ }^{33}$ with a lognormal relaxed clock ${ }^{34}$ resulted in the best fit (Supplementary Table S2) and was used in further analyses. We used a GTR nucleotide substitution model with gamma-distributed rate variation among sites.

Markov Chain Monte Carlo (MCMC) analyses of the combined dataset were run for 200 million generations (with $10 \%$ burn-in). We then ran the Bayesian skyline analysis for 150 million generations (with $10 \%$ burn-in) under the same evolutionary model for the two Ukrainian clades separately to estimate fluctuations in effective population size $\left(N_{e}\right)$ for these two clades. Convergence of the MCMC sampler was inspected using Tracer. ${ }^{35}$

Estimates of effective reproductive number. The effective reproductive number $\left(R_{e}\right)$ of an epidemic is the average number of secondary infections attributable to an infected person. This value is often used to describe transmission dynamics in a population; $R_{e}>1$ means the epidemic is growing, while $R_{e}<1$ means the epidemic is declining. We used the phylodynamic birth-death model ${ }^{36}$ implemented in BEAST, v2.4.7, ${ }^{37}$ to estimate $R_{e}$ for the two Ukrainian clades.

We ran MCMC analyses for 150 million generations (10\% burn-in). As before, we used a GTR nucleotide substitution model with gamma-distributed rate variation among sites. We applied a uniform prior for the date of origin of both clades, with a mean value of 50 years (lower bound $=0.0$ and upper bound $=100.0$ ). The sampling proportion was set to 0 before the first sampling date (2002 for both clades). After that a beta distribution prior was applied to the sampling proportion parameter $(\alpha=1.0$ and $\beta=10.0)$, with a constraint between $0.1 \%$ and $10 \%$. We used a lognormal distribution prior for $R_{e}($ mean $=1.0$ and standard deviation $=1.25)$ and a normally distributed TMRCA prior for each of the two clades, using values of the TMRCA estimated in the previous analysis using the combined dataset (see Results section). We also assumed that the infectivity period, which is the period between contracting the virus and becoming uninfectious (being in treatment and virally suppressed, or dying), was, on average, 4 years for a patient in Ukraine; this parameter was fixed. To assess the robustness of our results to this assumption, we performed additional sensitivity analyses for this parameter by considering four additional values for the infectivity period: $1,2,6$, and 8 years, which correspond to rates of becoming uninfectious of $1.0,0.5,0.167$, and 0.125 per year.

\section{Results}

Ukrainian HIV-1 subtype B sequences $(n=120)$ were obtained from patients belonging to four transmission groups: PWID $(n=26)$, MSM $(n=32)$, HET (non-PWID heterosexuals) $(n=54)$, and mother-to-child transmission (MTC, $n=8)$. Most of the Ukrainian sequences $(75 \%, n=90)$ were from male patients. Regarding their geographic distribution, 73 of the sequences $(61 \%)$ came from Kyiv, 29 (24\%) from Mykolaiv, and the remaining regions $(N=9)$ were represented by $\leq 5$ sequences each (Table 1 ). The geographical distribution of the subtype B dataset used here is more representative than Ukrainian HIV-1 subtype B sequences available from the Los Alamos database (Fig. 1a), but is less extensive than that of the dominant HIV-1 subtype A in Ukraine (Fig. 1b).

Figure 1c shows the ML phylogenetic tree estimated from the combined dataset. This phylogeny reveals two clades that mostly contained Ukrainian sequences $(\geq 75 \%)$ : Clades 1 and 2 , with SH-like support values of 0.99 and 0.86 , respectively. Clade 1 contains 65 sequences ( 53 sequences from Ukraine, 4 from Finland, 3 from Germany, and 1 sequence each from United States, United Kingdom, Kenya, Belgium, and Japan). Clade 2 contains 71 sequences (53 sequences from Ukraine, 4 from Russia, 4 from Georgia, 2 each from Azerbaijan, Czech Republic, and Luxembourg, and 1 each from Belarus, Uzbekistan, Slovenia, and Italy).

A comparison of sociodemographic characteristics of Clades 1 and 2 is presented in Table 1 . Clade 1 contains more sequences from Mykolaiv (Fisher's exact test $p$-value <.001). Sequences from Eastern Europe/Central Asia were more prevalent in Clade 2 (Fisher's exact test $p$-value <.001). There was no significant difference between the two clades in terms of transmission group or gender composition. Clade 2 had more CASCADE sequences (chi-square test $p$-value $=$ .003) than Clade 1. We also compared sociodemographic characteristics of the sequences appearing in one of the two clades versus those that did not. Sequences in the two clades were more likely to be Ukrainian (chi-square test $p$-value <.001) and were less likely to be sampled in other parts of the world than Eastern Europe and Central Asia (Fisher's exact test $p$-value <.001).

The AI analysis showed transmission group admixture for both clades: AI values for Clades 1 and 2 are 4.32 ( $p$-value .32 ) and 4.45 ( $p$-value .60), respectively. The mean pairwise genetic distance was $2.9 \%$ in Clade 1 and $1.8 \%$ in Clade $2(t$ test $p$-value <.001). Since Clade 2 had lower pairwise genetic diversity, and included sequences from other FSU countries, this clade can be identified as the $\mathrm{B}_{\mathrm{FSU}}$ strain, previously reported in the literature as originating from Mykolaiv. ${ }^{7,14}$

A regression of sampling time against root-to-tip genetic divergence showed a strong temporal signal in the combined dataset (correlation coefficient $=0.61$ ), but weaker signal when the two Ukrainian clades were analyzed separately (correlation coefficients 0.3 and 0.27 for Clade 1 and Clade 2, respectively) (Supplementary Fig. S1). Therefore, we first ran a BEAST analysis on the combined dataset and estimated TMRCAs of Clades 1 and 2 to be 1971 [95\% highest posterior density (HPD) 1956-1978] and 1973 (95\% HPD 19651978), respectively. These dates were then used as priors on the TMRCA parameter for all subsequent Bayesian phylogenetic analyses. 
Table 1. Sociodemographic Characteristics of the Ukrainian Sequences

\begin{tabular}{|c|c|c|c|c|c|c|c|c|c|c|}
\hline \multicolumn{3}{|c|}{ Full dataset } & \multicolumn{2}{|c|}{ Clade 1} & \multicolumn{2}{|c|}{ Clade 2} & \multirow{2}{*}{$\begin{array}{l}\text { Chi-square/ } \\
\text { Fisher's } \\
\text { exact test: } \\
\text { Clade 1 vs. } \\
\text { Clade 2 } \\
\mathrm{p}\end{array}$} & \multirow{2}{*}{$\begin{array}{c}\begin{array}{c}\text { Not in } \\
\text { Clade 1 } \\
\text { or Clade } 2\end{array} \\
\mathrm{~N}\end{array}$} & \multicolumn{2}{|c|}{$\begin{array}{c}\text { Chi-square/Fisher's } \\
\text { exact test: } \\
\text { "In the clades" } \\
\text { vs. "Not" }\end{array}$} \\
\hline Variable & $\mathrm{N}$ & $\%$ & $N$ & $\%$ & $\mathrm{~N}$ & $\%$ & & & $\%$ & $\mathrm{p}$ \\
\hline \multicolumn{11}{|l|}{ All sequences } \\
\hline \multicolumn{11}{|l|}{ Sampling region } \\
\hline Ukraine & 120 & 40.1 & 53 & 81.5 & 53 & 74.7 & .409 & 14 & 8.6 & $<.001$ \\
\hline $\begin{array}{l}\text { Eastern Europe/ } \\
\text { Central Asia }\end{array}$ & 32 & 10.7 & 0 & 0 & 15 & 21.1 & $<.001$ & 17 & 10.4 & 0.87 \\
\hline World & 147 & 49.2 & 12 & 18.5 & 3 & 4.2 & .012 & 132 & 81.0 & $<.001$ \\
\hline Total & 299 & 100.0 & 65 & 100.0 & 71 & 100.0 & - & 163 & 100.0 & - \\
\hline \multirow{2}{*}{\multicolumn{11}{|c|}{$\begin{array}{l}\text { Only Ukrainian sequences } \\
\text { Gender }\end{array}$}} \\
\hline & & & & & & & & & & \\
\hline Male & 90 & 75.0 & 38 & 71.7 & 43 & 81.1 & .253 & 9 & 64.3 & .32 \\
\hline Female & 30 & 25.0 & 15 & 28.3 & 10 & 18.9 & .253 & 5 & 35.7 & .32 \\
\hline \multicolumn{11}{|l|}{ Risk group } \\
\hline HET & 54 & 45.0 & 21 & 39.6 & 23 & 43.4 & .693 & 10 & 71.4 & .03 \\
\hline PWID & 26 & 21.7 & 13 & 24.5 & 11 & 20.7 & .642 & 2 & 14.3 & .732 \\
\hline MTC & 8 & 6.7 & 7 & 13.2 & 1 & 1.9 & .06 & 0 & 0 & .594 \\
\hline MSM & 32 & 26.6 & 12 & 22.7 & 18 & 34.0 & .176 & 2 & 14.3 & .667 \\
\hline \multicolumn{11}{|l|}{ Region } \\
\hline Kyiv & 73 & 60.8 & 25 & 47.2 & 39 & 73.5 & .005 & 9 & 64.3 & .78 \\
\hline Mykolaiv & 29 & 24.2 & 25 & 47.2 & 2 & 3.8 & $<.001$ & 2 & 14.4 & .514 \\
\hline Vinnytsya & 5 & 4.2 & - & - & 4 & 7.5 & .118 & 1 & 7.1 & .468 \\
\hline Odessa & 3 & 2.5 & 2 & 3.7 & 1 & 1.9 & 1 & 0 & 0 & 1 \\
\hline Dnipro & 2 & 1.7 & - & - & 1 & 1.9 & 1 & 1 & 7.1 & .221 \\
\hline Kharkiv & 2 & 1.7 & - & - & 2 & 3.8 & .495 & 0 & 0 & 1 \\
\hline Sumy & 2 & 1.7 & - & - & 2 & 3.8 & .495 & 0 & 0 & 1 \\
\hline Kherson & 1 & 0.8 & - & - & - & - & 1 & 1 & 7.1 & .117 \\
\hline Ivano-Frankivsk & 1 & 0.8 & - & - & 1 & 1.9 & 1 & 0 & 0 & 1 \\
\hline Lugansk & 1 & 0.8 & 1 & 1.9 & - & - & 1 & 0 & 0 & 1 \\
\hline Zhytomyr & 1 & 0.8 & - & - & 1 & 1.9 & 1 & 0 & 0 & 1 \\
\hline \multicolumn{11}{|l|}{ Data source } \\
\hline $\begin{array}{l}\text { Ukrainian HIV } \\
\text { drug resistance } \\
\text { database }\end{array}$ & 46 & 38.3 & 24 & 45.3 & 14 & 26.4 & .04 & 8 & 57.2 & .12 \\
\hline CASCADE & 65 & 54.2 & 24 & 45.3 & 36 & 67.9 & .003 & 5 & 35.7 & .63 \\
\hline $\begin{array}{l}\text { Los Alamos } \\
\text { database }\end{array}$ & 9 & 7.5 & 5 & 9.4 & 3 & 5.7 & .716 & 1 & 7.1 & 1 \\
\hline Total & 120 & 100.0 & 53 & 100.0 & 53 & 100.0 & - & 14 & 100.0 & - \\
\hline
\end{tabular}

Values in bold indicate statistically significant $p$-values accounting for Bonferroni correction for multiple comparisons.

HET, heterosexuals; MSM, men who have sex with men; MTC, mother-to-child transmission; PWID, people who inject drugs.

The molecular clock trees of the two clades are presented in Figure 2a and $\mathrm{b}$. When we analyzed the two clades separately, we obtained TMRCA estimates consistent with the analysis of the combined dataset (1967, 95\% HPD 19561976, and 1975, 95\% HPD 1968-1981, for Clade 1 and Clade 2, respectively) (Fig. 2c, d), as expected given the use of a strong TMRCA prior. For both clades, the values of the number of HIV infections in HET and PWID were almost a magnitude higher than the $N_{e}$ estimated by Bayesian skyline plots, and these values for MSM were magnitudes lower than $N_{e}$ estimates until the last 10 years (Fig. 2c, d). The $N_{e}$ of Clade 1 steadily grew over two orders of magnitude until 2017. The $N_{e}$ of Clade 2 grew $\sim 2.5$ orders of magnitude within the same period; however, this clade appears to have experienced more rapid growth between 1980s and late 1990s. The overall number of reported HIV cases per year in HET and PWID, but not MSM, agree well with the estimated $N_{e}$ curves for Clade 2 (Fig. 2d).

We estimated $R_{e}$ for Clades 1 and 2 to be 1.42 (95\% HPD 1.26-1.56) and 1.69 (95\% HPD 1.49-1.84), respectively, under the assumption that the infectivity period is 4 years (Fig. 3). When we performed additional sensitivity analyses for the $R_{e}$ parameter, we found that (as expected) estimated values of $R_{e}$ increase as the infectivity period increases. Estimated $R_{e}$ remained between 1 and 2 if the infectivity period is assumed to be $\leq 4$ years. If the infectivity period is considered to be $>4$ years, then $R_{e}$ gradually increases for both clades, with a particularly high $R_{e}$ for Clade $2\left(R_{e}=2.42,95 \%\right.$ HPD 2.04-2.8) if we assume an infectivity period of 8 years. Importantly, the $R_{e}$ of Clade 2 was consistently higher than 



FIG. 1. (a) The number and geographical distribution of HIV-1 subtype B sequences in the combined dataset. (b) The number and geographical distribution of HIV-1 subtype A sequences available from the Ukrainian Drug Resistance database in 2012-2015. Administrative units highlighted in red indicate newly sampled regions that were not represented in the Los Alamos HIV sequence database before this study. Pie charts for the Kyiv and Mykolaiv regions represent the proportions of sequences from these regions belonging to Clade 1 (light green), Clade 2 (dark green), or neither (gray). (c) The maximum likelihood phylogeny of the combined dataset with highlighted Clades 1 and 2. The colors at the tips represent the sampling regions. The bar at the bottom represents genetic distance. Values at the nodes for Clades 1 and 2 represent SH-like statistical support. Color images are available online.

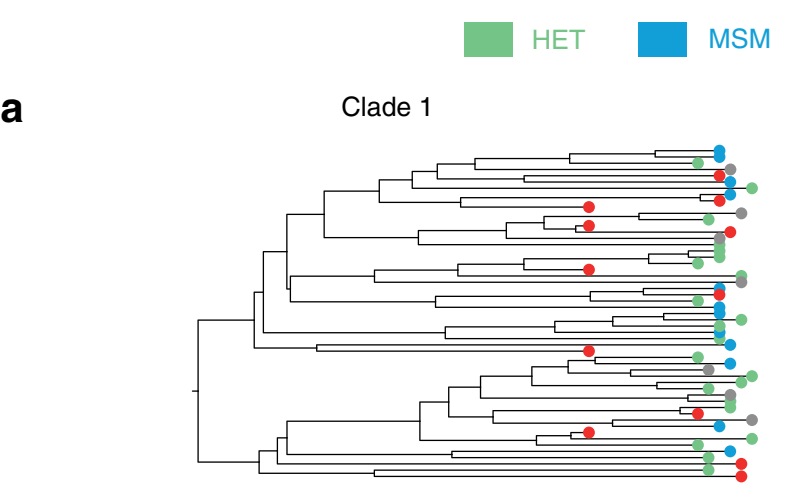

c

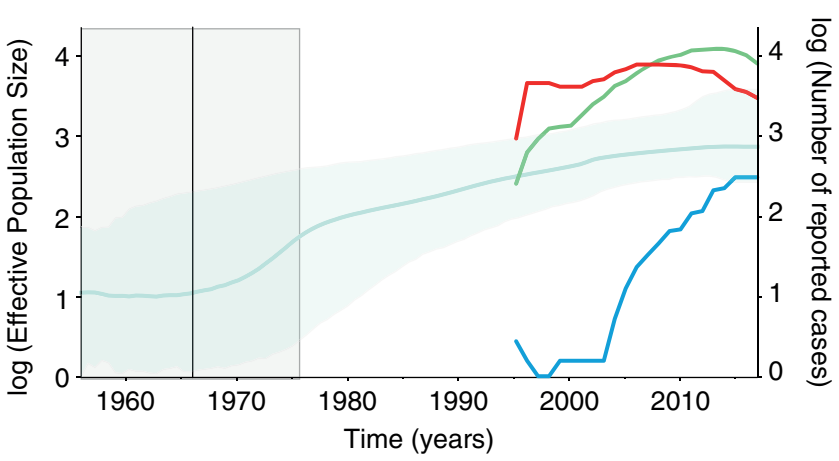

b

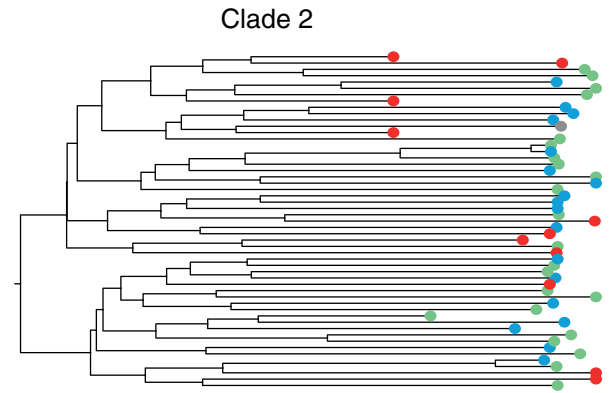

d

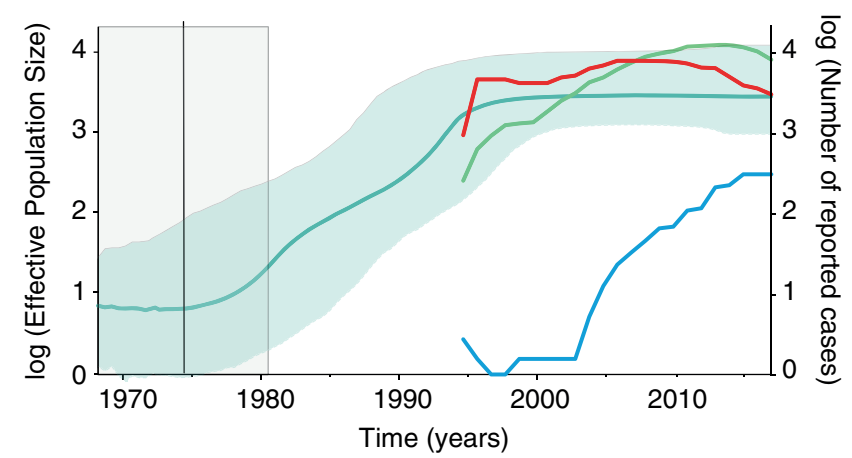

FIG. 2. (a, b) Molecular clock trees for Clades 1 and 2, respectively. The colors at the tree tips represent patients' risk group. (c, d) Bayesian skyline plots for Clades 1 and 2, respectively. The shaded green area highlights the 95\% HPD credible region. The black vertical lines and the shaded gray area represent the TMRCA and its 95\% HPD credible region. The colored lines with the right $y$-axis represent the log number of reported HIV cases per risk group. HPD, highest posterior density; TMRCA, time to most recent common ancestor. Color images are available online. 


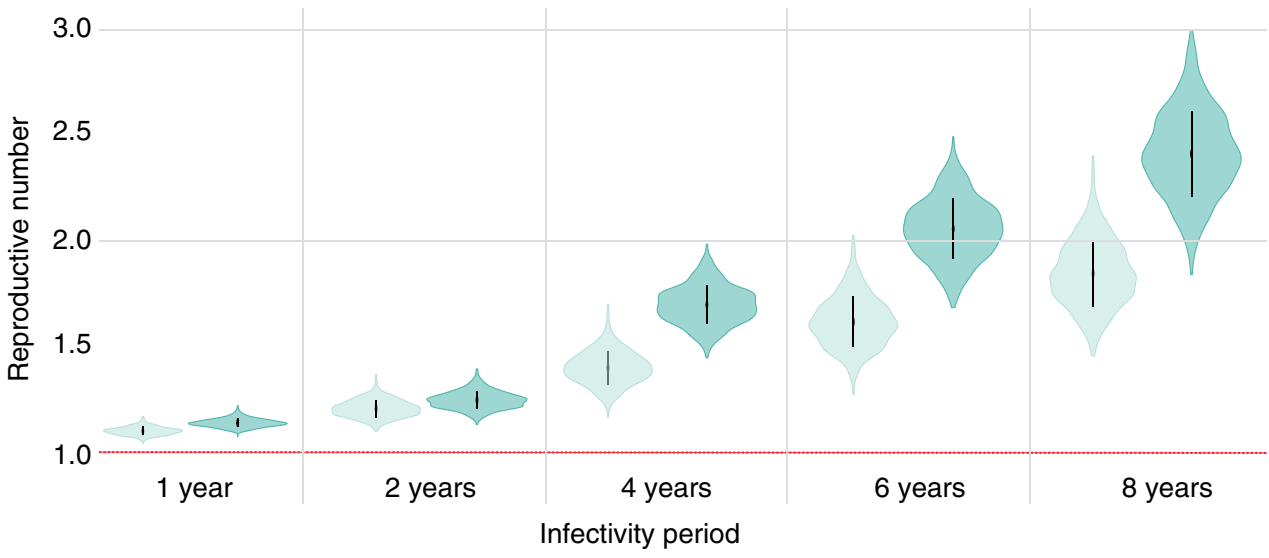

FIG. 3. Estimates of the effective reproductive number $\left(R_{e}\right)$ for each clade, assuming different durations of infectivity. The horizontal red dotted line represents the epidemiological threshold $\left(R_{e}=1\right)$. Vertical lines within violin plots reflect the second quartile of the $R_{e}$ distribution. Color images are available online. that of Clade 1 regardless of the specific value of the infectivity period used.

\section{Discussion}

HIV-1 subtype A has dominated the epidemic in Ukraine and other FSU countries since the mid-1990s. ${ }^{38}$ The molecular epidemiology of subtype A in Ukraine has been well described in the late 1990s, when this HIV subtype was discovered in the country, ${ }^{10,13}$ and in recent years. ${ }^{8,11,17}$ However, very few studies were published between 2000 and 2015 even though the number of new HIV cases continued to grow rapidly in the early to late 2000 s. $^{3,39,40}$ The molecular epidemiology of HIV-1 subtype B in Ukraine has been mostly neglected, primarily due to its lower prevalence. In this study, we characterize the current molecular epidemiology of HIV-1 subtype B in Ukraine, including its transmission group composition and virus transmission dynamics.

Previous reports have suggested that the HIV-1 subtype B epidemic in Ukraine started with the introduction of this subtype into the drug-injecting community of Mykolaiv in 1990s. ${ }^{7,41}$ In 2001-2002, HIV-1 subtype B was mostly prevalent in Mykolaiv $(N=22)$, followed by Kyiv $(N=18)$, and few cases reported in Odessa. ${ }^{7}$ Two HIV-1 subtype B lineages were found circulating in Kyiv, ${ }^{7}$ which is consistent with our findings here. However, the geographic distribution of HIV-1 subtype B sequences in our study is quite different: the majority of HIV-1 subtype B sequences come from Kyiv (61\% of the Ukrainian dataset) or other regions (15\%). This could be explained by a potential selection bias in the CASCADE data, ${ }^{17}$ sampled exclusively in Kyiv. Among the available 46 HIV-1 subtype B sequences in the Ukrainian HIV Drug Resistance database, 24 (52\%) originate from Mykolaiv, followed by small numbers of sequences from 9 other regions across Ukraine.

We find that Clade 2 (assigned as $\mathrm{B}_{\mathrm{FSU}}$ ) is now found mostly in HET in Kyiv, even though it was previously identified predominantly in Mykolaiv's PWID population. ${ }^{7,15}$ The estimated effective population size of Clade 2 $\left(\mathrm{B}_{\mathrm{FSU}}\right)$ is congruent with the yearly number of HIV cases in both PWID and HET in Ukraine $^{3}$ (Fig. 2d).

Overall, our analysis indicates a lack of transmission group structure for both clades, suggesting frequent viral mixing among transmission groups. Importantly, by analyzing the largest dataset of subtype B from Ukraine to date, we show that Ukrainian HIV-1 subtype $\mathrm{B}, \mathrm{B}_{\mathrm{FSU}}$ in particular, is no longer concentrated in selected regions (i.e., Mykolaiv and Kyiv) or in specific transmission groups. Similar observations of the expansion of $\mathrm{B}_{\mathrm{FSU}}$ from PWID to other transmission groups have been made in Russia where HIV-1 subtype B sequences isolated from MSM patients clustered with $\mathrm{B}_{\mathrm{FSU}}$ sequences collected from PWID. ${ }^{42}$

We also estimated the average reproductive number $R_{e}$ for the two clades of HIV-1 subtype B circulating in Ukraine. We found that Clade $2\left(\mathrm{~B}_{\mathrm{FSU}}\right)$ has a consistently higher $R_{e}$ than Clade 1 regardless of the infectivity period value used. The $R_{e}$ values estimated for both clades (1.42 and 1.69, assuming an infectivity period $=4$ years) were above one, indicating epidemic growth, but much lower than the $R_{e}$ value previously estimated at the beginning of the HIV-1 subtype A epidemic in Ukraine in the 1990s $\left(R_{e}=10\right.$ per drug injector, although it is likely to be lower now). ${ }^{12}$ This difference in epidemic potential could be related to differences in drug use practices between PWID in the two cities, where subtypes A and B were first discovered (Odessa and Mykolaiv for subtypes A and $\mathrm{B}$, respectively), or other cultural dissimilarities between the two cities, as described before. ${ }^{41}$ While Odessa had a large international port and also a large number of tourists, Mykolaiv was more isolated with some access restrictions during the Soviet era due to its close connection to the Soviet navy. ${ }^{41}$ This could be one of the explanations why HIV-1 subtype A rapidly became dominant in Ukraine, while HIV-1 subtype B remains less common to this day.

Another explanation is the first-comer advantage, which hypothesizes that the first successfully established founder strain can significantly slow down the spread of other strains in the region by either inhibiting superinfection, due to stimulation of anti-HIV immune responses and exhaustion of the number of target cells, or by reducing the number of susceptible noninfected individuals. ${ }^{43}$ For example, analyses of HIV-1 subtypes A and D in Uganda suggest that subtype A would need to have $25 \%$ transmission advantage compared with the first comer, subtype D, to establish an epidemic. ${ }^{43}$ The TMRCA of Ukrainian HIV-1 subtype A was previously estimated to be around 1970 (95\% HPD 1962-1976), ${ }^{11}$ which is similar to the TMRCAs estimated here for HIV-1 subtype B Clade 2 (1973, 95\% HPD 1965-1978) and Clade 1 (1971, 95\% HPD 1956-1978). 
Thus, our data suggest the approximately simultaneous introduction of HIV-1 subtypes A and B into Ukraine. However, the smaller number of HIV-1 subtype B sequences in our analysis, compared with previous HIV-1 subtype A studies, is associated with comparatively large confidence intervals for the estimates here. Further studies with more sequence data should provide a better understanding of the possible effects of first-comer advantage, if any, of HIV-1 subtypes in Ukraine.

One of the limitations of this study is that the data came from three different sources with different sampling techniques and different data collection methods for self-reported transmission group information. In particular, CASCADE data were collected anonymously, while data at the AIDS centers were collected by doctors in a nonanonymous manner. In our sample, $75 \%$ of patients were male; interestingly, $67 \%$ of HET patients were also male. MSM are often stigmatized and, as a consequence, this transmission group tends to be underreported in many settings, including Western Europe. ${ }^{4-46}$ We cannot exclude the possibility that some patients may have incorrectly self-reported as belonging to the non-MSM group in Ukraine. Similarly, PWID might not have disclosed their drug-injecting practices to AIDS center clinicians, particularly due to the stigma against HIV and drug use in medical facilities in Ukraine. ${ }^{47,48}$ As a result, underreporting of MSM and PWID status could overestimate the true proportion of HET in our study and thereby make the Ukrainian HIV-1 subtype B epidemiological profile look different from that of predominantly MSM-driven subtype B epidemics in Russia ${ }^{49}$ and some European countries. ${ }^{50}$

Furthermore, our sample is likely to represent a very small proportion of existing HIV-1 subtype B infections in Ukraine $(<1 \%)$. This is partly due to high rates of undiagnosed HIV infections in Ukraine, particularly in some transmission groups (such as MSM) ${ }^{51}$ As very few patients have access to drug resistance testing, ${ }^{8}$ viral genetic data from routine care are also very sparse.

We found that the epidemiological profile of the HIV-1 subtype B epidemic in Ukraine has recently changed. Specifically, HIV-1 subtype B is no longer limited to the PWID subpopulation and is spreading to multiple transmission groups throughout the country. As with HIV-1 subtype A in Ukraine, the subtype B epidemic appears to have generalized to HET, a much larger susceptible population, which could fuel the spread of HIV in Ukraine. Our data also suggest that HIV-1 subtype B in Ukraine is not concentrated in MSM, unlike the situation in Western Europe. Although the Ukrainian HIV-1 subtype B epidemic appears to be growing comparatively slowly, and is characterized by a lower $R_{e}$, its increasing range across locations and transmission groups highlights the need for better surveillance, linkage to care, antiretroviral treatment, and monitoring across the country.

\section{Ethical Approval}

HIV drug resistance testing was performed at the L.V. Gromashevskij Institute of Epidemiology and Infectious Diseases of National Academy of Sciences of Ukraine following all Ukrainian legal and ethical requirements. Fully anonymized genetic sequence data were transferred to Oxford through a Material Transfer Agreement for molecular evolutionary analyses.
Ethical approval for CASCADE was given by the ethics committee of the L.V. Gromashevskij Institute of Epidemiology and Infectious Diseases of National Academy of Sciences of Ukraine and the ethics committee of University College London (UCL).

\section{Acknowledgments}

T.I.V. is supported by the Clarendon Fund and Hertford College of the University of Oxford. N.R.F. is funded by a Royal Society and Wellcome Trust Sir Henry Dale Fellowship (grant 204311/Z/16/Z). CASCADE was supported by the European Union Seventh Framework Programme (FP7/ 2007-2013) under EuroCoord (grant agreement no. 260694). Accession Nos. are MH577242-MH577287.

\section{Author Disclosure Statement}

No competing financial interests exist.

\section{References}

1. European center for disease prevention and control: HIV/AIDS Surveillance in Europe 2015. European Centre for Disease Prevention and Control/WHO Regional Office for Europe, Stockholm, 2016.

2. Dehne KL, Grund JC, Khodakevich L, Kobyshcha Y: The HIV/AIDS epidemic among drug injectors in Eastern Europe: Patterns, trends and determinants. J Drug Issues 1999;29:729-776.

3. МоН: ОПЕРАТИВНА ІНФОРМАЦІЯ про офіційно зареєстровані випадки ВІЛ-інфекції, СНІДу та кіль кість смертей, зумовлених СНІДом, за березень 2017 pоку. [Operational Information on Officially Ergistered Cases of HIV, AIDS, and the Numbers of AIDS Deathes, as of March 2017]. Ukrainian Centres to Prevent and Fight AIDS, Kyiv, 2017.

4. Vitek CR, Čakalo JI, Kruglov YV, et al.: Slowing of the HIV epidemic in Ukraine: Evidence from case reporting and key population surveys, 2005-2012. PLoS One 2014;9: e103657.

5. Liitsola K, Tashkinova I, Laukkanen T, et al.: HIV-1 genetic subtype $\mathrm{A} / \mathrm{B}$ recombinant strain causing an explosive epidemic in injecting drug users in Kaliningrad. AIDS 1998;12:1907-1919.

6. Nikolopoulos GK, Kostaki EG, Paraskevis D: Overview of HIV molecular epidemiology among people who inject drugs in Europe and Asia. Infect Genet Evol 2016;46:256268 .

7. Saad MD, Shcherbinskaya AM, Nadai Y, et al:: Molecular epidemiology of HIV type 1 in Ukraine: Birthplace of an epidemic. AIDS Res Hum Retroviruses 2006;22:709714.

8. Vasylyeva TI, Liulchuk M, Friedman SR, et al:: Molecular epidemiology reveals the role of war in the spread of HIV in Ukraine. Proc Natl Acad Sci U S A 2018;115:10511056.

9. Kuiken C, Korber B, Shafer RW: HIV sequence databases. AIDS Rev 2003;5:52-61.

10. Novitsky VA, Montano MA, Essex M: Molecular epidemiology of an HIV-1 subtype A subcluster among injection drug users in the Southern Ukraine. AIDS Res Hum Retroviruses 1998;14:1079-1085. 
11. Díez-Fuertes F, Cabello M, Thomson MM: Bayesian phylogeographic analyses clarify the origin of the HIV-1 subtype A variant circulating in former Soviet Union's countries. Infect Genet Evol 2015;33:197-205.

12. Vasylyeva TI, Friedman SR, Lourenco J, et al.: Reducing HIV infection in people who inject drugs is impossible without targeting recently-infected subjects. AIDS 2016; 30:2885-2890.

13. Bobkov A, Kazennova E, Selimova L, et al.: A Sudden Epidemic of HIV type 1 among injecting drug users in the Former Soviet Union: Identification of subtype A, subtype $\mathrm{B}$, and novel gagA/envB recombinants. AIDS Res Hum Retroviruses 1998;14:669-676.

14. Bobkova M: Current status of HIV-1 diversity and drug resistance monitoring in the former USSR. AIDS Rev 2013;15:204-212.

15. Saad MD, Aliev Q, Botros BA, et al.: Genetic forms of HIV Type 1 in the former Soviet Union dominate the epidemic in Azerbaijan. AIDS Res Hum Retroviruses 2006;22:796800 .

16. Kazennova E, Laga V, Lapovok I, et al.: HIV-1 genetic variants in the Russian Far East. AIDS Res Hum Retroviruses 2014;30:742-752.

17. Fearnhill E, Gourlay A, Malyuta R, et al.: A phylogenetic analysis of human immunodeficiency virus type 1 sequences in Kiev: Findings among key populations. Clin Infect Dis 2017;65:1127-1135.

18. Simmons R, Malyuta R, Chentsova N, et al.: HIV testing and diagnosis rates in Kiev, Ukraine: April 2013-March 2014. PLoS One 2015;10:e0137062.

19. Pineda-Peña AC, Faria NR, Imbrechts $S$, et al.: Automated subtyping of HIV-1 genetic sequences for clinical and surveillance purposes: Performance evaluation of the new REGA version 3 and seven other tools. Infect Genet Evol 2013;19:337-348.

20. Struck D, Lawyer G, Ternes AM, Schmit JC, Bercoff DP: COMET: Adaptive context-based modeling for ultrafast HIV-1 subtype identification. Nucleic Acids Res 2014;42: e144.

21. Altschul SF, Madden TL, Schäffer AA, et al:: Gapped BLAST and PSI-BLAST: A new generation of protein database search programs. Nucleic Acids Res 1997;25: 3389-3402.

22. Sievers F, Wilm A, Dineen D, et al.: Fast, scalable generation of high-quality protein multiple sequence alignments using Clustal Omega. Mol Syst Biol 2011;7:539.

23. Kumar S, Stecher G, Tamura K: MEGA7: Molecular evolutionary genetics analysisversion 7.0 for bigger datasets. Mol Biol Evol 2016;33:1870-1874.

24. Bennett DE, Camacho RJ, Otelea D, et al.: Drug resistance mutations for surveillance of transmitted HIV-1 drug-resistance: 2009 Update. PLos One 2009;4:e4724.

25. Stamatakis A: RAxML version 8: A tool for phylogenetic analysis and post-analysis of large phylogenies. Bioinformatics 2014;30:1312-1313.

26. Shimodaira $H$, Hasegawa M: Multiple comparisons of loglikelihoods with applications to phylogenetic inference. Mol Biol Evol 1999;16:1114-1116.

27. Guindon S, Dufayard JF, Lefort V, Anisimova M, Hordijk W, Gascuel O: New Algorithms and methods to estimate maximum-likelihood phylogenies: Assessing the performance of PhyML 3.0. Syst Biol 2010;59:307-321.

28. Rambaut A, Lam TT, Max Carvalho L, Pybus OG: Exploring the temporal structure of heterochronous sequences using TempEst (formerly Path-O-Gen). Virus Evol 2016;2: vew007.

29. Parker J, Rambaut A, Pybus OG: Correlating viral phenotypes with phylogeny: Accounting for phylogenetic uncertainty. Infect Genet Evol 2008;8:239-246.

30. Lemey P, Rambaut A, Drummond AJ, Suchard MA: Bayesian phylogeography finds its roots. PLoS Comput Biol 2009;5:e1000520.

31. Gelman A, Meng XL: Simulating normalizing constants: From importance sampling to bridge sampling to path sampling. Stat Sci 1998;13:163-185.

32. Xie WG, Lewis PO, Fan Y, Kuo L, Chen MH: Improving marginal likelihood estimation for Bayesian phylogenetic model selection. Syst Biol 2011;60:150-160.

33. Drummond AJ, Rambaut A, Shapiro B, Pybus OG: Bayesian coalescent inference of past population dynamics from molecular sequences. Mol Biol Evol 2005;22:11851192.

34. Drummond AJ, Ho SY, Phillips MJ, Rambaut A: Relaxed phylogenetics and dating with confidence. PLoS Biol 2006; 4:e88.

35. Rambaut A, Drummond AJ, Xie D, Baele G, Suchard MA: Posterior summarization in Bayesian phylogenetics using Tracer v1.7. Syst Biol 2018;67:901-904.

36. Stadler T, Kouyos R, von Wyl V, et al.: Estimating the basic reproductive number from viral sequence data. Mol Biol Evol 2012;29:347-357.

37. Bouckaert R, Heled J, Kühnert D, et al.: BEAST 2: A software platform for bayesian evolutionary analysis. PLoS Comput Biol 2014;10:e1003537.

38. Aibekova L, Foley B, Hortelano G, et al.: Molecular epidemiology of HIV-1 subtype A in former Soviet Union countries. PLos One 2018;13:e0191891.

39. Barcal K, Schumacher JE, Dumchev K, Moroz LV: A situational picture of HIV/AIDS and injection drug use in Vinnitsya, Ukraine. Harm Reduct J 2005;2:16.

40. Kruglov YV, Kobyshcha YV, Salyuk T, Varetska O, Shakarishvili A, Saldanha VP: The most severe HIV epidemic in Europe: Ukraine's national HIV prevalence estimates for 2007. Sex Transm Infect 2008;84 Suppl 1: i37-i41.

41. Nabatov AA, Kravchenko ON, Lyulchuk MG, Shcherbinskaya AM, Lukashov VV: Simultaneous introduction of HIV type 1 subtype A and B viruses into injecting drug users in southern Ukraine at the beginning of the epidemic in the former Soviet Union. AIDS Res Hum Retroviruses 2002;18:891-895.

42. Kazennova E, Laga V, Gromov K, et al.: Genetic variants of HIV type 1 in men who have sex with men in Russia. Aids Res Hum Retroviruses 2017;33:10611064.

43. Ferdinandy B, Mones E, Vicsek T, Müller V: HIV competition dynamics over sexual networks: First comer advantage conserves founder effects. Plos Comput Biol 2015; 11:e1004093.

44. Hué S, Brown AE, Ragonnet-Cronin M, et al:: Phylogenetic analyses reveal HIV-1 infections between men misclassified as heterosexual transmissions. AIDS 2014;28: 1967-1975.

45. van de Laar TJ, Bezemer D, van Laethem K, et al.: Phylogenetic evidence for underreporting of male-to-male sex among human immunodeficiency virus-infected donors in the Netherlands and Flanders. Transfusion 2017;57:12351247. 
46. Esbjörnsson J, Mild M, Audelin A, et al.: HIV-1 transmission between MSM and heterosexuals, and increasing proportions of circulating recombinant forms in the Nordic Countries. Virus Evol 2016;2:vew010.

47. Kiriazova T, Postnov O, Bingham $\mathrm{T}$, et al.: Patient and provider perspectives inform an intervention to improve linkage to care for HIV patients in Ukraine. BMC Health Serv Res 2018;18:58.

48. Malta M, Ralil da Costa M, Bastos FI: The paradigm of universal access to HIV-treatment and human rights violation: How do we treat HIV-positive people who use drugs? Curr HIV AIDS Rep 2014;11:52-62.

49. Karamov E, Epremyan K, Siniavin A, et al.: HIV-1 genetic diversity in recently diagnosed infections in Moscow: Predominance of AFSU, frequent branching in clusters, and circulation of the Iberian subtype G variant. AIDS Res Hum Retroviruses 2018;34:629-634.
50. Paraskevis D, Pybus O, Magiorkinis G, et al:: Tracing the HIV-1 subtype B mobility in Europe: A phylogeographic approach. Retrovirology 2009;6:49.

51. Simmons R, Malyuta R, Chentsova N, et al.: HIV incidence estimates using the limiting antigen avidity EIA assay at testing sites in Kiev city, Ukraine: 2013-2014. PLoS One 2016;11:e0157179.

Address correspondence to:

Tetyana I. Vasylyeva

Department of Zoology

University of Oxford

Peter Medawar Building

South Parks Road

Oxford OX1 3SY

United Kingdom

E-mail: tetyana.vasylyeva@zoo.ox.ac.uk 